\title{
MATERNIDADE MAMÍFERA? CONCEPÇÕES SOBRE NATUREZA E CIÊNCIA EM UMA REDE SOCIAL DE MÃES
}

\author{
Fernanda Vecchi Alzuguir \\ Marina Nucci ${ }^{2}$
}

\begin{abstract}
RESUMO
Subsidiadas por estudos do campo do gênero e ciência, em especial os trabalhos de Londa Schiebinger, propomos uma reflexão a respeito das considerações sobre natureza e evidências cientificas que emergem em torno do parto e da amamentação, a partir do estudo de caso de um blog utilizado por mães que se identificam como "mamíferas". Observamos que as narrativas analisadas se apoiam em evidencias científicas para legitimar o ideário da humanização e a noção de que as mulheres são uma extensão da natureza. Paradoxalmente, as narrativas demonstram que a defesa da humanização do parto e da amamentação está ancorada em um determinismo biológico, cujos efeitos no sentido da perpetuação das relações desiguais de gênero já foram há décadas apontados por estudos feministas. Problematizamos a noção de natureza expressa nas "redes mamíferas" a fim de desatar seus nós biologizantes e evidenciar a potência política do ativismo nas redes sociais de mães.
\end{abstract}

Palavras-chave: Mamíferas. Gênero. Natureza. Maternidade.

\footnotetext{
${ }^{1}$ Professora Adjunta do Instituto de Estudos em Saúde Coletiva, da Universidade Federal do Rio de Janeiro, Brasil. fevecchi@iesc.ufrj.br

${ }^{2}$ Doutoranda em Saúde Coletiva no Instituto de Medicina Social, da Universidade Estadual de Rio de Janeiro, Brasil. marinanucci@gmail.com
} 


\title{
MAMMALIAN MOTHERHOOD? CONCEPTIONS ABOUT SCIENCE AND NATURE IN A MOTHERHOOD-ORIENTED SOCIAL NETWORK
}

\begin{abstract}
Assisted by gender and science studies, especially by Londa Schiebinger's works, we aim to reflect upon the notions of nature and scientific evidences which emerge around giving birth and breastfeeding, based on the case study of a blog targeted by mothers who identify themselves as "mammalians". We noticed that the analyzed narratives support themselves in scientific evidences in order to legitimate the ideal of humanization and the notion that women are an extension of nature. Paradoxically, the narratives show that the advocacy of childbirth humanization and breastfeeding is grounded in a biological determinism, which effects towards the perpetuation of unequal gender relations have been pointed out by feminist studies for decades. We have questioned the notion of nature, as portrayed in "mammalian networks", to untie biologizing knots and expose the political power of activism in motherhood-oriented websites.
\end{abstract}

Keywords: Mammalian. Gender. Nature. Motherhood.

\section{INTRODUÇÃO}

s reflexões que propomos aqui são provenientes das nossas observações
acerca do fenômeno da maternidade a partir da aproximação das autoras
em relação ao tema sob diferentes prismas. Para uma delas, o trabalho pregresso no atendimento hospitalar a gestantes, puérperas e bebês de "alto risco" foi um campo rico de construção do conhecimento sobre as intervenções e preocupações médico-sanitárias acerca do corpo feminino e da relação mãe-bebê. Esse cenário também permitiu a observação das tensões entre a lógica que rege 0 paradigma biomédico e aquela que orienta as percepções de mulheres em relação aos cuidados com o corpo, saúde e doença, nem sempre coincidentes. Para outra autora, a aproximação com o tema da maternidade se deu através de sua participação em uma rede virtual formada por mães brasileiras de classe média cujos diálogos transcorriam em grupos virtuais e blogs criados e acessados por mães para compartilhar experiências sobre temas como parto, amamentação, cuidado e saúde dos filhos.

A despeito de suas diferenças, os contextos descritos são atravessados por uma questão comum, que parece ser um ponto nevrálgico sobre o qual se tece a micropolítica de gênero nas sociedades ocidentais contemporâneas, mas que tem 
profundas raízes no pensamento Iluminista de meados do século XVIII e XIX. Referimo-nos à forte valorização da ideia de uma "natureza feminina" a partir do desenho de uma continuidade traçada entre mulheres e o reino animal, por meio da aproximação delas com a classificação taxonômica dos mamíferos.

Instigadas por essas questões, propomos uma reflexão sobre os discursos e as práticas em torno do parto e da amamentação, no contexto dos movimentos contemporâneos de defesa da humanização da assistência à mulher. Partimos de um estudo de caso das narrativas de um dos blogs do portal denominado "Maternidade Ativa - Vila Mamífera". Analisamos os posicionamentos que aparecem nos discursos de mães brasileiras de classe média de centros urbanos para compartilhar suas experiências acerca da maternidade e que se identificam como "mães mamíferas".

A escolha pela análise das narrativas de um blog especifico se justifica por considerarmos que ele é representativo de concepções sobre natureza e ciência, presentes em um grupo particular formado no interior das redes sociais utilizadas por mães ${ }^{4}$. Problematizamos os argumentos que se apoiam numa noção de natureza feminina universal como recurso de legitimação da autonomia reprodutiva feminina, a fim de propor outras possibilidades discursivas e de agenciamento que não reforcem, mas sim problematizem a equação mulhernatureza.

A partir da reflexão teórica de estudos do campo do gênero e ciência, em especial, através do trabalho de Schiebinger (1998), destacaremos o contexto social e político de perpetuação da noção de que as mulheres são uma extensão da natureza e 0 importante papel da ciência como matriz de naturalização da condição feminina, a partir dos processos reprodutivos das mulheres.

Em relação ao empreendimento científico, nosso olhar se volta para a maneira como o discurso científico é ressignificado nas redes virtuais de mães, para legitimar práticas e estilos de vida consoantes com 0 ideário da humanização do parto e da amamentação ancorados na ideia de uma natureza feminina universal. Essa apropriação se evidencia no importante lugar ocupado pelas evidências científicas nos textos dos blogs para corroborar as concepções sobre maternidade, configurando assim, um campo que designaremos aqui como

\footnotetext{
${ }^{3}$ vilamamifera.com/olharmamifero/

${ }^{4}$ Essa representatividade, verificada pelas autoras a partir de um mapeamento preliminar mais geral de vários blogs do portal, justifica a possibilidade de incluir também em nossa análise a citação de outro blog (KASIN, 2014) como fonte secundária.
} 
"maternidade baseada em evidências". Destacamos que não se trata de invalidar a relevância social e política dos dispositivos das redes sociais de mães como rede de suporte, no sentido da construção da autonomia reprodutiva e sexual das mulheres e da crítica à medicalização do corpo feminino. Ao contrário, propomos chamar a atenção para a urgência de uma análise crítica da ideia de uma natureza feminina universal já que tal ideia, em última instância, ancora em um determinismo biológico os argumentos em prol da luta por uma maternidade mais "autônoma" e "consciente". Dessa forma, tal ideia de natureza não coloca em questão as condições sociais de emergência das desigualdades de gênero e, consequentemente, a dimensão política da maternidade.

Optamos por focalizar nos relatos sobre amamentação e parto, tendo em vista o rendimento analítico desses temas como domínios privilegiados de enunciação da identidade das "mães mamíferas" e de afirmação da autonomia reprodutiva das mulheres. Além disso, a maneira como ambos os eventos são narrados expressa uma situação de liminaridade entre humanos e animais e, assim, mostram-se eventos privilegiados para analisarmos as concepções sobre a relação entre natureza e cultura.

A seguir apresentamos a perspectiva teórica sobre gênero e ciência da qual partimos. Descrevemos, posteriormente, algumas características gerais do grupo social das "mamíferas". Em nossa análise, tentamos elucidar como que, ao redor do parto e da amamentação, uma concepção particular sobre a natureza das "mamíferas" se articula com as chamadas "evidências científicas" e o lugar de destaque que explicações acerca do funcionamento do hormônio ocitocina adquire nesse cenário. Ao final, subsidiadas pelo estudo de Schiebinger (1998) a respeito da história política da classificação "mamíferos", como elo de união entre humanos e alguns animais, propomos uma reflexão crítica sobre os limites decorrentes da ideia de natureza feminina universal nas narrativas analisadas.

\footnotetext{
${ }^{5}$ Como observa Tornquist (2002), o chamado movimento da humanização do parto incorpora a noção de "medicina baseada em evidências", concepção que critica a medicina convencional pelo uso e abuso de valores tidos como "extracientíficos", baseados em crenças ou tradições consideradas "ultrapassadas" e sem respaldo científico.

${ }^{6}$ A ideia de uma maternidade consciente e autônoma pode ser sintetizada nas noções de "protagonismo feminino" e "maternidade ativa", abordadas mais adiante.
} 


\section{GÊNERO, NATUREZA E CIÊNCIA}

Desde o advento do Iluminismo, a ciência é um poderoso veículo de produção e legitimação de verdades sobre a ordem social. No que tange ao gênero e sexualidade e os complexos dilemas ético-morais provenientes desse campo não foi diferente.

Vários estudos contemporâneos irão problematizar as relações entre gênero, sexualidade e ciência através do desvelamento da dimensão social, histórica e política de todo empreendimento científico, incluindo os estudos no campo das "ciências naturais". Autores como Laqueur (2001) e Schiebinger (1998) demonstram como, no contexto político de defesa dos ideários de igualdade e liberdade, as desigualdades de gênero passam a ser legitimadas, justificadas e (re)produzidas pela ciência a partir da diferenciação dos corpos femininos e masculinos. Sendo assim, com o advento da ciência moderna, a natureza biológica de dois corpos irredutíveis se torna a base inquestionada - pois supostamente neutra - de justificação da ordem desigual de gênero.

Refletindo o clássico dualismo natureza e cultura e, a partir dele, a divisão entre as ciências naturais e humanas, ao longo da constituição desses campos disciplinares, cada um deles se encarregou da investigação de diferentes objetos sob perspectivas também diferentes. Enquanto corpo e sexo eram domínios, até há pouco tempo, restritos às ciências biomédicas, as ciências sociais investigavam os determinantes socioculturais que incidiam sobre uma realidade biológica (corpo) "autoevidente".

A partir de fins de 1980, começam a emergir de forma mais marcante estudos críticos de gênero e ciência, como, por exemplo, os trabalhos de Ruth Bleier (1988), Anne Fausto-Sterling (1992), Donna Haraway (1989), Evelyn Fox Keller (1999), entre outras, que passaram a problematizar o estatuto do corpo natural a partir de uma imersão das ciências humanas "para dentro" das ciências ditas naturais. Tal visão permite colocar em questão de forma mais radical, as bases do determinismo biológico, sobre o qual as desigualdades de gênero historicamente se assentam.

Os estudos sociais da ciência desvelaram as condições de emergência dos fatos científicos, ao evidenciar como sua fabricação no campo das ciências biológicas não escapa de contingencias sócio-políticas; além de questionar 0 estatuto de natureza do próprio corpo e do sexo. Desse modo, sexo e corpo, antes domínios restritos das ciências naturais, passam a ser objeto de reflexão do campo das ciências sociais e humanas. Esse é o caso dos trabalhos de autoras que, por 
terem formação em ciências biológicas, ficaram conhecidas como "biólogas feministas" e que analisaram, entre outras questões, como a própria constituição de substâncias químicas, como os hormônios sexuais "femininos" e "masculinos", é modulada pelo dualismo de gênero (OUDSHOORN, 1994; WIJNGAARD, 1997).

Munidas dessa perspectiva crítica, pretendemos refletir sobre as armadilhas de uma acepção particular sobre natureza feminina universal que vem se esboçando em determinadas redes sociais de mães. Iniciaremos nossa análise com uma breve apresentação de algumas características gerais do universo das "mães mamíferas".

\section{AS MÃES MAMÍFERAS $\mathrm{E}$ AS NARRATIVAS SOBRE PARTO $\mathrm{E}$ AMAMENTAÇÃO}

Podemos observar atualmente uma profusão de blogs, sites, e grupos brasileiros em redes sociais na internet em torno da gravidez e da maternidade, recheados de depoimentos pessoais e informações de todo tipo, que vão desde dicas para a compra do enxoval do bebê, até discussões em torno da melhor forma de se criar os filhos. Embora existam também blogs escritos por pais, a maioria deles é feito por mães e para mães, desempenhando um lugar importante de sociabilidade e construção coletiva de identidade materna no contexto da classe média urbana.

Dentro desta variedade de blogs sobre maternidade, destacamos uma corrente que se auto intitula como "mamíferas", e que defende o que chamam de uma "maternidade ativa" e "consciente", calcada no "protagonismo" e "empoderamento" feminino.

A maternidade ativa ou consciente se refere tanto à adoção de orientações cientificas sobre 0 cuidado com os bebês, como à tomada de consciência sobre a capacidade de fazer escolhas em torno da maternagem (POMBO, 2013). Dentre os diversos pontos enfatizados pelas "mamíferas", destaca-se a defesa do parto natural e humanizado (domiciliar e hospitalar), a amamentação "prolongada" (durante dois anos ou mais) e em livre demanda (sem horários rígidos prédeterminados, isto é, sempre que o bebê solicitar 0 seio). Refletindo um ideário ecologista que perpassa as correntes alternativas e naturalistas, tributárias do

70 termo empoderamento é utilizado sem muitas conceitualizações, e acaba ganhando significados diversos em diferentes contextos. De modo geral, porém, ele se refere aqui ao processo de conquista de consciência e autonomia pela mulher. 
pensamento da contracultura da década de 1960 (TORNQUIST, 2002), as "mamíferas" preconizam também a ideia de um "retorno à natureza" e a valorização de um "sagrado feminino". Isso pode ser ilustrado nas tentativas de importar as práticas africanas e indígenas de parto e de cuidado com os bebês, consideradas mais próximas da "natureza".

As mães mamíferas questionam a perda do protagonismo no cuidado dos filhos, devido à terceirização do cuidado, e valorizam a dimensão de um prazer instintual da mulher enquanto materna. Os discursos importam as concepções do chamado attachment parenting ${ }^{8}$, corrente que, sob a influência da teoria do apego ${ }^{9}$, preconiza a importância do vínculo mãe-bebê para 0 bem-estar e desenvolvimento saudável da criança (POMBO, 2013).

A análise dos textos sobre parto e amamentação, no blog pesquisado, desvela uma concepção particular sobre natureza e sua relação com a maternidade. Uma das noções prementes é a ideia de que a natureza do corpo feminino é "perfeita e sábia", sendo tarefa da mulher, que vai parir e amamentar um bebê, reconhecer e se entregar aos seus ditames.

0 parto e a amamentação "naturais" são acontecimentos singulares de expressão e valorização da "natureza" do corpo feminino. Um dos atributos que qualificam como "naturais" esses eventos é justamente a possibilidade de dispensar intervenções médico-tecnológicas como, por exemplo, todo o aparato hospitalar implicado na cirurgia cesárea, bem como o uso de mamadeiras, leites industrializados e bicos de silicone, no caso da amamentação.

A despeito da nítida vertente de desmedicalização do corpo feminino como diretriz defendida para a consecução de uma maternidade "mais natural", "ativa" e "empoderada", tal vertente se apoia, paradoxalmente, na ciência - a partir do respaldo em "evidências científicas" - como matriz privilegiada de legitimação das práticas humanizadas de parto e amamentação.

No blog que analisamos há uma seção sobre partos acompanhados pela sua autora (que também é doula ${ }^{10}$ e fotógrafa), junto a uma equipe de parto humanizado de um hospital do SUS que é tido como uma referência para o parto

\footnotetext{
${ }^{8}$ www.attachmentparenting.org

${ }^{9}$ A teoria do apego foi desenvolvida pelo psiquiatra e psicanalista John Bowlby (1999), quem, sob a influência de saberes como a etologia, a psicologia e a psicanálise investigou os processos de formação do vínculo de bebês a partir das suas primeiras relações.

${ }^{10}$ Profissional que acompanha o parto com o objetivo de proporcionar apoio físico e emocional às mulheres.
} 
humanizado. Verificamos certo padrão de organização da estrutura das narrativas. Várias fotografias tiradas pela autora do blog são apresentadas para ilustrar três momentos: gestação, parto e pós-parto imediato. As fotos da gestação são ensaios do casal em ambientes como cachoeira e campo, que transmitem uma ideia de harmonia, romance e felicidade a dois no projeto da maternidade. Consoante com a defesa do parto vaginal humanizado, a maioria dos casos retratam o sucesso do parto vaginal domiciliar ou em hospital de referência para o parto humanizado.

As imagens do parto vaginal são marcadas por expressões faciais que transmitem a impressão de dor e prazer pela mulher no momento do parto. Também destacam a presença e o apoio do companheiro ao longo do processo. No pós-parto, observa-se o predomínio da foto da mãe e do companheiro com o bebê, por vezes com a presença de outros familiares, com foco na correspondência de um olhar enternecido do casal em direção ao bebê e deste para os pais.

Essas imagens se interpõem às descrições textuais sobre 0 acompanhamento de cada parto em particular. As narrativas são geralmente poéticas, com metáforas e figuras de linguagem que imprimem um tom romântico ao parto e à amamentação: "Olhe as palavras e saiba que por aqui, escrever é com o coração na ponta dos dedos para deixar a poesia fluir em imagens e palavras que falam com sua alma" (BRUM, s.d.).

Ao mesmo tempo, trazem uma preocupação em fundamentar e comprovar a defesa da humanização do parto e da amamentação a partir de evidências científicas. Como um exemplo, a descrição de um parto domiciliar de uma gestante que procurou a autora do blog, aos 34 meses de gestação, para ser acompanhada por ela, e que começa com a pergunta se já havia pensado no parto domiciliar ao invés do hospitalar. Assim, de acordo a autora: "Ela disse que nunca havia pensado, não. Mas o que você acha? E lá fui eu enviando evidências científicas, sempre reforçando que independentemente do local ela poderia ter um parto natural maravilhoso" (BRUM, 2014a).

Logo mais adiante, reaparece a alusão ao embasamento científico como recurso de legitimação das práticas humanizadas:

Em seu lar, com a tranquilidade necessária, com equipe embasada em evidência científica ela celebrou o nascimento com a junção das velhas tradições com o mais moderno: escolher parir em casa e ter assistência com embasamento científico para que 0 parto volte a ser um evento protagonizado pela mulher. (BRUM, 2014a) 


\section{OCITOCINA: HORMÔNIO DO AMOR?}

Neste cenário paradoxal, de reforço das evidências científicas em nome da desmedicalização do parto e da amamentação, destaca-se um importante ator: 0 hormônio ocitocina, e seu papel crucial na consecução do parto e da amamentação naturais.

Também conhecida como "hormônio do amor" (ODENT, 2000), a ocitocina é retratada como uma aliada das "mamíferas" no trabalho de parto e na expulsão do bebê, em uma espécie de dança conjunta com a adrenalina e as endorfinas. A ocitocina também é aliada da mãe na amamentação, pois está implicada no processo fisiológico de ejeção do leite das glândulas mamárias.

Mais do que aliada, a ocitocina aparece nas narrativas como prova científica da própria natureza mamífera feminina. Para a produção/ativação da ocitocina no parto e na amamentação é necessária a estimulação do corpo da mãe pelo bebê. No primeiro caso, isso é explicado pelo contato do bebê com a saída da parede uterina, enquanto que na amamentação sua produção é estimulada pela sucção do seio materno pelo bebê.

A ocitocina também aparece nos depoimentos das "mamíferas" como sinônimo de amor e felicidade. É comum o uso de frases como: "estou ocitocinada até agora!” para se referir a uma experiência feliz ou emocionante, 0 que revela a incorporação e ressignificação desta linguagem hormonal ao vocabulário cotidiano.

Em um estudo realizado a partir de várias mídias (websites, revistas, programas de rádio e televisão nos anos de 1989-2012), Fillod (2014) analisa a disseminação da "teoria da ocitocina" na França a partir de 2000. Mais especificamente, analisa como que, a despeito da não confirmação científica dos estudos clínicos e experimentais com animais e humanos, a teoria da ocitocina se disseminou na cultura francesa e serviu de suporte para a defesa, por grande parte da população, da ideia de que o "instinto materno" não era mito, mas uma realidade. Essa disseminação incrementou as discussões na mídia francesa acerca das considerações de Elisabeth Badinter $(1985,2010)$ sobre a desnaturalização da noção de instinto materno, a partir de uma análise da variabilidade de formas de maternar em diferentes contextos históricos e políticos.

Segundo Fillod (2014), a teoria da ocitocina afirma que o hormônio ativa circuitos cerebrais que promoveriam o vínculo afetivo. Desse modo, como o parto e a estimulação do mamilo causam um aumento nos níveis de ocitocina na mulher, constatou-se que parto e amamentação teriam o efeito fisiológico de 
promover o vínculo mãe-bebê, sendo caracterizado como o "hormônio do amor materno". Retomando os estudos realizados com animais e humanos, Fillod (2014) argumenta que seus resultados não confirmam a teoria. Mesmo assim, ela foi validada pela mídia francesa e por especialistas de diferentes campos, como a pediatria, a primatologia, a sociobiologia, a neurobiologia, a neuroendocrinologia, dentre outros. Entre as hipóteses levantadas para a disseminação acrítica da teoria da ocitocina, a autora menciona o poderoso lugar da biologia como suporte para as distinções de gênero. Assim, segundo Fillod (2014), atualmente na França 0 gênero aparece regido mais pela mística dos hormônios do que sobre a mística do DNA.

A premência do discurso sobre a ocitocina nos blogs das redes sociais das mamíferas evidencia a disseminação da teoria também no contexto brasileiro. Entre as influências citadas nessas redes sociais, destacam-se os trabalhos do médico francês Michel Odent, defensor, desde a década de 1970, do parto vaginal humanizado, e cujas concepções sobre a ocitocina podem ser lidas no livro $A$ cientificação do amor ${ }^{11}$.

\section{PARTO VAGINAL E PRAZER SEXUAL}

Narrativas com intuito de demonstrar a aproximação entre parto vaginal, amamentação e prazer são recorrentes e respaldadas, como veremos, pela teoria da ocitocina. Nas matérias sobre o chamado "parto orgásmico", uma clara analogia é tecida entre 0 parto vaginal e 0 orgasmo na relação sexual, como podemos observar no fragmento abaixo da matéria Parir e Gozar da revista TPM ${ }^{12}$ :

...é possível sentir as contrações com prazer. Isso porque a mulher, assim como cada fêmea do reino animal, possui um sistema reprodutivo perfeitamente organizado para a manutenção da espécie, garantindo que gestar e parir sejam experiências seguras - e até

\footnotetext{
${ }^{11}$ Ver ODENT, Michel, 2000 e 2002. A presença de Odent também é destaque no recente documentário brasileiro "O Renascimento do Parto" (2013), de Érica de Paula e Eduardo Chauvet, cuja produção foi financiada, em sua maior parte, por ativistas da humanização do parto, através de campanhas na internet. No filme, Odent explicita a importância, durante 0 parto e 0 nascimento, do que chama de um coquetel de "hormônios do amor". Além disso, Odent argumenta que o que ocorre no nascimento pode ser crucial para o desenvolvimento ou não de diversas condições patológicas, doenças ou desvios de personalidade.

${ }^{12}$ A inclusão da matéria da revista em nossa análise se justifica em razão desta apresentar depoimentos da autora do blog além de seu link ter sido por ela citado em uma postagem.
} 
prazerosas. Num parto vaginal, livre de intervenções médicas, 0 organismo se encarrega de produzir os próprios analgésicos (DANELON, 2009, s/p, grifo nosso).

Novamente, a ocitocina entra em ação para atestar essa relação. Em um post intitulado "6 passos para ter um orgasmo no parto", a autora do blog tece algumas condições que favoreceriam o parto "orgásmico" (BRUM, 2014b). Sendo assim, a apresentação do segundo passo, ocorre da seguinte maneira: "0 hormônio que rege o parto é a ocitocina. 0 hormônio responsável pelo orgasmo sexual é... ocitocina. As mesmas condições que nos preparamos para uma boa transa deveria ser o modo como planejamos nosso parto" (BRUM, 2014b).

A segunda parte do post é ocupada por um texto do obstetra Ricardo Herbert Jones, defensor do parto humanizado. Ele reflete sobre a existência de algo para "além do corpo", que estaria envolvido na experiência de dor e prazer durante o parto, ao lado dos processos fisiológicos, aludindo, neste caso, à dimensão do "sentimento e emoções".

Porém, a despeito da valorização da dimensão sacralizada "para além do corpo", 0 argumento principal do médico que fundamenta toda a possibilidade do prazer no parto reside, de fato, no terreno profano ocupado pelo corpo biológico, através da ação dos hormônios, como se observa na narrativa do médico:

Michel Odent, médico francês radicado em Londres chama [a ocitocina] de "o hormônio do amor", porque está presente sempre que um momento amoroso se expressa, como no parto e no encontro sexual. (...) Fácil fica, para qualquer observador perspicaz, que existe um claro paralelismo entre os eventos do parto e os do sexo, fazendonos enxergar pela primeira vez o nascimento inserido nas forças sexuais de uma mulher (JONES apud BRUM, 2014b).

Atravessando as narrativas do blog, a ideia é que as mulheres devem relaxar e assim se entregar ao fluxo, à lógica e à temporalidade da natureza de seu corpo. A oposição natureza e cultura fica bem demarcada e hierarquizada, de maneira que a segunda se define como tudo aquilo que não é da fisiologia do corpo e ganha uma conotação muitas vezes negativa, em contraposição à ordem da natureza. Cultura aqui aparece como tudo aquilo que corrompe, constrange e distancia a mulher de sua "verdadeira natureza". Seguindo essa linha, cultura se confunde com as tecnologias médicas, modismo e consumismo. 
Neste sentido, por exemplo, a narrativa sobre 0 resgate de um prazer natural (que, como vimos, é "naturalmente" produzido pela ocitocina) é tanto mais legítima, quanto mais distante das intervenções externas ao corpo. Assim, retomando o paralelo entre prazer sexual e parto, o médico da matéria anterior ressalta que parto orgásmico não é uma técnica a ser buscada, mas sim um "segredo bem guardado", que emerge "naturalmente" a partir de um "mergulho profundo no eu feminino" e do distanciamento das amarras do poder patriarcal em relação à sexualidade feminina.

Destacamos a importância dos depoimentos de especialistas (como obstetras, ginecologistas, psicanalistas), comprometidos com a humanização do parto, em vários blogs e revistas destinadas ao público feminino, no sentido da legitimação dos discursos sobre parto e amamentação naturais, especialmente quando os referidos veículos abordam temas polêmicos como é o caso da relação entre parto e sexo. Como ilustração, transcrevemos outro depoimento da matéria Parir e Gozar, do ginecologista obstetra Carlos Czeresnia:

Os movimentos de distensão e contração do períneo no momento em que 0 bebê vai sair são muito semelhantes à sensação do orgasmo. E 0 cérebro interpreta esses estímulos neurais como respostas de prazer. 0 parto e o orgasmo percorrem o mesmo caminho neurológico (CZERESNIA apud DANELON, 2009).

As narrativas analisadas vão colorindo o grupo das "mães mamíferas" que assim adquire forma e identidade. Entre as características que as definem, destacamos a noção de que elas são uma extensão das fêmeas do reino animal. Tal noção parece se acentuar nos contextos do parto e da amamentação, provavelmente por serem situações que evocam nas narrativas uma situação de liminaridade entre humanos e animais. Ilustrando essa questão, observamos depoimentos de mulheres sobre a sensação de que "viraram bichos" durante 0 parto natural ou da relação com a "cria" - termo comumente usado para designar o bebê - durante a amamentação. Como vemos no depoimento da autora do blog que analisamos na matéria Parir e Gozar:

Lembro da sensação quente, do escorregar daquele pequeno corpo pelas minhas entranhas. Eu estava ali, nua, fêmea, selvagem, desfrutando do prazer mais intenso que já vivi. Um longo orgasmo selou sua passagem para esta vida, quebrando com o paradigma de que nascer é sofrer (BRUM apud DANELON, 2009, grifo nosso). 
Os especialistas convocados nesta matéria comprovam as afirmações de que tais eventos deflagram um "retorno a uma natureza mais primitiva", mediante explicações sobre a reativação (via hormônios) de regiões cerebrais "primitivas" e o desligamento do néocórtix, responsável pela razão. Nas palavras de um médico: "Ouça os gritos de uma mulher durante o parto: são guturais. Urros instintivos que emergem da parte mais primitiva de seu cérebro." (ADAILTON apud DANELON, 2009).

0 mesmo médico argumenta que as atividades físicas perderam espaço para as atividades intelectuais, as quais predominam na "era da razão". Segundo ele: "Nesse clima competitivo, a mulher vive sob adrenalina, fabricando mais testosterona" e conclui que o sistema imunológico da mulher estaria, portanto, "desvitalizado" (ADAILTON apud DANELON, 2009).

A afirmação anterior chama bastante atenção por sua concepção sobre as diferenças de gênero. Pois, uma nítida aproximação entre mulher, físico e natureza se desenha como símbolo de saúde, em contraposição ao poder destrutivo do uso da razão pelas mulheres. Surpreendentemente, o "problema" se relaciona à intensificação das atividades intelectuais (córtex cerebral) pelas mulheres, o que acarretaria a fabricação de testosterona, hormônio vinculado ao masculino. Aqui se observa como o dualismo de gênero informa os estudos dos hormônios, como diversas autoras já demonstraram ao analisar as pesquisas sobre hormônios sexuais (OUDSHOORN, 1994; MANICA, 2011; ROHDEN, 2008, 2011; NUCCI, 2010).

Os discursos que aproximam a mulher dos "bichos ancestrais" reavivam, em última instância, a noção, já observada por Fillod (2014), de um instinto materno que emerge na experiência do parto e da amamentação, a despeito do poder de desconexão exercido pela cultura e seus excessos. À "mãe mamífera" se imprime uma dimensão marcadamente sacralizada nos relatos sobre 0 parto natural. Esse tratamento é observado na maneira como a parturiente - designada, muitas vezes, como uma "deusa" - é reverenciada.

0 trecho abaixo foi retirado de um post sobre o acompanhamento da segunda gestação de uma mulher submetida a uma cesárea em sua primeira gestação, sem indicação clínica, na qual sofreu situações de violência obstétrica.

Hoje uma mulher foi respeitada e uma parteira ajoelhou aos seus pés para receber seu filho. Uma mulher parindo está num pedestal, perto dos céus e nós nos esticamos para tocar sua essência, agora curada, pelo filho parido, pelo parto respeitoso, pelo protagonismo que 
abraçou suas entranhas, saiu como grito por sua boca e como filho por sua vagina. Hoje mais uma mulher foi tratada como deusa (BRUM, 2014c).

Nota-se que o parto vaginal é retratado como uma forma de reparação da dor e do trauma, devido aos excessos tecnológicos e da alienação do corpo, sofrido no primeiro parto. Mas, o mesmo também é uma via através da qual é possível resgatar uma "essência feminina", cuja conexão foi perdida no primeiro parto.

De forma semelhante às narrativas sobre parto vaginal, os discursos sobre amamentação traçam uma íntima relação entre amamentação e prazer. Mais uma vez, a ocitocina é chamada para comprová-la. Dessa forma, postula-se que 0 comportamento amoroso maternal persiste após o parto natural, devido ao aumento da taxa de ocitocina no corpo da mulher. Conforme o post a seguir, de outro blog sobre maternidade:

A amamentação é também um processo natural e primitivo. A prolactina é o principal hormônio para a saída do leite e a ocitocina atua na saída do mesmo. Quando o bebê suga, os níveis de ocitocina estão em alta. 0 nível de endorfinas chega ao máximo em 20 minutos de amamentação, gerando prazer e relaxamento para mãe e bebê... (KASIN, 2014).

As funções reprodutivas das "mamíferas" durante a amamentação e o parto são glorificadas como um "destino natural das mulheres" e como expressão do "empoderamento feminino", como ilustra o trecho a seguir:

Quando a uma mulher é dado o direito de parir naturalmente e sua vagina cumpre prazerosamente uma função que independe da figura masculina; quando os seios alimentam pelo prazer e biologia que contém neste ato, há uma quebra de paradigma cultural. A mulher retoma o prazer em suas funções biológicas e desassocia a sexualidade da necessidade de dar prazer ao homem (BRUM, 2014d).

E mais adiante, a respeito do tema da amamentação: "Seus seios agora exercem a função para a qual foram feitos, que fazem com que sejamos chamadas de mamíferas". (BRUM, 2014d). Neste post fica também evidente a vinculação da cultura com o masculino, o qual desvirtuaria os desígnios predeterminados da natureza do corpo reprodutivo feminino. Neste sentido, a crítica, no mesmo post, sobre a ordem social vigente que atribui: "ao seio sua função não biológica de 
apenas ser um objeto de desejo masculino. A vagina poupada de sua função de parir estará apenas para servir à função cultural de dar prazer ao homem" (BRUM, 2014d). Sendo assim, a "quebra do paradigma cultural" (aquele que corromperia o curso natural do corpo feminino) é reivindicada através da defesa de um retorno à biologia dos seios e da vagina, às funções para as quais foram originalmente feitas, quais sejam, amamentar e parir, respectivamente.

As narrativas demonstram que a defesa da humanização do parto e da amamentação está ancorada em um determinismo biológico, cujos efeitos, no sentido da perpetuação das relações desiguais de gênero, já foram há décadas apontados por estudos feministas. Cabe, portanto, uma reflexão crítica sobre a noção de natureza expressa nas redes mamíferas, a fim de desatar seus nós biologizantes e evidenciar a potência política do ativismo nas redes sociais de mães.

\title{
O PROBlEMA DA NATUREZA COMO DESTINO. REFLEXÕES CRÍTICAS SOBRE O ASSENTO NO DETERMINISMO BIOLÓGICO PARA A DEFESA DO PARTO E DA AMAMENTAÇÃO NATURAIS
}

\begin{abstract}
NÃO DESANIME! A NATUREZA NÃO É MARAVILHOSA?
A folha impressa com esta mensagem da internet sobressaía do caderno de uma jovem sentada mais à frente. De onde eu estava, só dava para ler 0 título. Duas frases interligadas pelo capricho de alguém com excesso de entusiasmo. Ou de violência. Em geral não gosto de ponto de exclamação - usá-lo num título, então, é como cuspir na cara de alguém. E a natureza? A natureza é tão maravilhosa quanto um tornado, uma chuva ácida, uma praga de lagartas (ROBAYO, 2014, p. 54).
\end{abstract}

0 depoimento que inaugura essa seção faz parte de um interessante artigo da revista Piauí sobre a vivência de uma autora argentina enquanto mãe, em especial, sobre sua experiência com a amamentação. A descrição inicial decorre da observação da autora em um curso de preparação para gestantes do qual participou. Este singelo relato de experiência traz uma importante problematização a respeito do estatuto da natureza na perspectiva de quem vive a maternidade no cotidiano.

Robayo (2014) chama a atenção para os slogans e frases comuns pronunciadas pelas puericultoras de incentivo à amamentação para mulheres 
que, como ela, procuraram apoio por enfrentarem dificuldades em amamentar. Nos serviços, a regra segundo a qual a natureza do corpo reprodutivo da mãe é sempre "sábia e perfeita" não parece dar conta da inclusão das mulheres que, como Robayo, enfrentaram dificuldades para amamentar "naturalmente", a despeito do apoio das puericultoras e do reconhecimento da importância do leite materno para a saúde do bebê.

$\mathrm{Na}$ seção anterior, procuramos mostrar que as narrativas sobre parto e amamentação das "mamíferas" se baseiam na sacralização de uma ideia de natureza, relacionada ao corpo reprodutivo de gestantes e puérperas, como suporte para a defesa da humanização do parto e da amamentação.

Nosso argumento diz respeito ao caráter problemático dos discursos que naturalizam a maternidade como extensão das fêmeas mamíferas, uma vez que eles assentam a política de humanização do parto e da amamentação sobre a concepção universalizante de que a biologia é destino natural das mulheres.

Muitos trabalhos do campo do gênero e ciência já destacaram o caráter social e político do processo de naturalização da reprodução feminina pelos discursos científicos, no contexto dos movimentos de reivindicação de igualdade e liberdade (LAQUEUR, 2001; SCHIEBINGER, 1986, 1998). Em um primoroso artigo intitulado Mamíferos, Primatologia e Sexologia, Londa Schiebinger (1998) empreende uma análise crítica sobre a instauração da classificação de Carlos Lineu dos mamíferos (a partir da introdução do termo Mammalia), na taxonomia zoológica em meados do século XVIII. Seu questionamento sobre as razões para a criação da categoria mamíferos conduz à análise do contexto histórico de instauração das nomenclaturas taxonômicas, a despeito de sua aparência de neutralidade.

Como já destacamos, distintas concepções sobre natureza, legitimadas pelo empreendimento cientifico, foram fabricadas e transformadas a partir do advento do Iluminismo. E no tocante à classificação dos mamíferos, ainda tão presente e naturalizada entre nós, não foi diferente.

Assim, envolvido com a questão do lugar dos humanos na natureza, Lineu uniu em sua classificação, humanos e animais, elegendo as mamas como o elo de união e semelhança. Ao mesmo tempo, Lineu apresentou a classificação "homo sapiens" para distinguir os humanos dos animais a partir de um elemento diferencial, a razão, que estaria presente apenas nos primeiros. Isso corrobora nossa observação de que a aproximação das mulheres com a dimensão da natureza é uma construção histórica relacionada à política de gênero. 0 mesmo 
ocorre para a valorização da razão como o elemento que tradicionalmente distinguiu os homens da "natureza" e permitiu sua inscrição na cultura.

Para Schiebinger (1998), a escolha das mamas (ao invés de outras características possíveis como pêlos, buracos nos ouvidos) está impregnada de um sentido político relacionado ao contexto da sociedade europeia da época. A preocupação com o desenvolvimento político e econômico da Europa se deu a partir da adoção de estratégias de diminuição da alta taxa de mortalidade infantil. Entre elas, as campanhas de aleitamento materno, ao lado das campanhas de abolição das amas de leite e da substituição das parteiras por médicos. De acordo com a autora, tudo que afastasse as mulheres das leis da natureza era visto como um risco para saúde materno-infantil. Justamente nesse contexto se disseminaram discursos segundo os quais as mães deveriam seguir seu "instinto animal" e, através dele, os ditames "naturais" das relações de proximidade das mulheres com as fêmeas do reino animal.

Os investimentos lançados pelas autoridades médicas (Lineu era médico e participou diretamente das campanhas de aleitamento materno) e o sistema legal em direção ao aleitamento materno não se explicam apenas por uma simples preocupação médico-sanitária a respeito da mortalidade infantil. A tarefa de fixação da mulher à esfera privada para dedicar-se aos cuidados com a prole e sua consequente exclusão da vida pública, contradizia o ideário igualitário burguês.

Schiebinger (1998) mostra, portanto, que a taxonomia dos mamíferos foi forjada dentro de um contexto sócio-político mais amplo no qual as desigualdades de gênero eram justificadas pela afirmação - legitimada pela ciência - do corpo reprodutivo feminino como destino.

Em uma resenha crítica do artigo de Schiebinger (1998), Pombo e Nucci (2014) ilustram como a própria ideia de natureza (e, com ela, a taxonomia mamífera) não é neutra em valores. Analisando criticamente os discursos das "mamíferas" sobre a amamentação, estas autoras consideram que o argumento de que "somos mamíferas e por isso devemos amamentar (e ter 0 direito a amamentar)" se ancora numa lógica determinista, da qual muitas mulheres tentaram se livrar há mais de um século.

A partir da crítica à ideia de natureza, as autoras levantam outros argumentos para a reivindicação do direito a amamentar, entre eles, o fato de ser uma estratégia de emancipação uma vez que o leite materno é de livre acesso e não depende de fórmulas caras. As autoras argumentam, entretanto, que mesmo a escolha por amamentar não ocorre sem custos para as mães por conta da 
situação de maior isolamento (no caso, ao espaço doméstico) e distanciamento dos espaços coletivos de muitas mulheres. Ainda afirmam que:

Se a sociedade continuar entendendo essa tarefa como extensão da natureza feminina, como uma função das fêmeas mamíferas, continuará a não arcar coletivamente com os custos corporais, temporais e econômicos do aleitamento e dos cuidados com as crianças pequenas. (POMBO; NUCCI, 2014)

Corroborando essa análise, destacamos as contribuições de Pombo (2013). Sem deixar de reconhecer a importância do ativismo virtual das "mamíferas" como espaço potente de troca de experiências pessoais, leituras e de instituições sobre 0 cuidado com os bebês, a autora levanta algumas questões fundamentais para nosso debate. Todas elas nascidas de uma primeira inquietação que nos é particularmente cara: “... se essas práticas [de maternagem] eram escolhas, por que colocá-las como um destino biologicamente determinado?” (POMB0, 2013, p. 35). Daí o questionamento subsequente: se as mães que não aderem às práticas mamíferas preconizadas não seriam por isso condenadas ao status de mães "desnaturadas".

Para Pombo (2013), os discursos que compõem a "maternidade ativa" encerram um paradoxo. Apesar de se constituírem como uma forma de resistência à lógica de reprodução capitalista e às práticas mainstream das mães de camadas médias - a exemplo da crítica em relação à terceirização dos cuidados dos filhos, aqueles discursos são, de fato, capturados pelo mesmo sistema capitalista ao buscarem legitimidade num aporte científico reducionista e ao apelarem para as escolhas individuais das mulheres.

Sendo assim, a autora argumenta que os discursos das mães mamíferas não problematizam a dimensão política do debate que diz respeito à escassez de políticas públicas de apoio às mães, de diferentes camadas sociais, para o cuidado na primeira infância. Assim, influenciadas pelos aportes da psicologia evolucionista e da corrente norte-americana do attachment parenting, trata-se a maternidade como uma questão individual (que diz respeito à díade mãe-bebê) e acaba por restringir a possibilidade de "escolha" às mães que dispõem de recursos (financeiros e apoio de terceiros) para se dedicarem à primeira infância, conforme as orientações para assegurar o "pleno desenvolvimento" do bebê (amamentação sob livre demanda, pronto atendimento ao choro, por exemplo). 
Além disso, no tocante ao que chamamos de "maternidade baseada em evidências", Pombo (2013) questiona a relação de dependência do protagonismo materno à validação dos especialistas dos critérios que definirão as melhores escolhas. Assim, a autora interroga se não haveria uma atualização do discurso higienista e da responsabilidade delegada às mães de preservar o bem-estar social através do cuidado dos filhos.

Os discursos de naturalização da maternidade têm sido apropriados por uma vertente mais conservadora que, amparada pelo reducionismo científico, acirra a divisão sexual do trabalho e a valorização de certo modelo de família (aquela formada por mãe e pais biológicos) (FILLOD, 2014; POMBO, 2013). Dessa forma, a naturalização do amor materno reforça a noção de uma identidade materna universal, que hierarquiza ou mesmo desconsidera diferentes formas de ser mãe e família (POMBO, 2013).

Concordamos com Pombo (2013) ao observar que a naturalização da maternidade fomentada por evidências científicas acaba por responsabilizar as mães biológicas pelo cuidado na primeira infância, deixando intacta uma discussão a respeito da responsabilidade do poder público em dar condições às mães para a gestão do cuidado materno. Disso resulta 0 esvaziamento da dimensão política da maternidade, ainda relegada ao domínio do feminino, do individual e do privado.

Procuramos mostrar o lugar central ocupado por uma acepção particular sobre natureza a partir de um blog que faz parte de um conjunto de redes virtuais das mães mamíferas em suas orientações sobre parto e amamentação.

Importante destacar que as narrativas das "mamíferas" se referem a um universo particular que traz, consequentemente, uma concepção também particular sobre natureza/cultura que não pode ser generalizada inadvertidamente para todas e todos que participam do movimento de defesa da humanização e saúde. Esse campo é marcado pela polissemia discursiva que configura variados níveis de entendimentos sobre natureza e cultura (CARNEIR0, 2014). Por se tratar ainda de um mapeamento inicial de um campo discursivo complexo, longe de encerrar o debate, nosso objetivo foi lançar questões para fomentar estudos futuros dos discursos sobre parto e amamentação no campo do ativismo virtual de mães. As narrativas analisadas evidenciam linhas de continuidades, mas também reconfigurações importantes das concepções clássicas de natureza. Um aspecto particular diz respeito à forte positivação da ideia de natureza do corpo feminino que imprime uma marca de superioridade em relação à cultura, de cujos constrangimentos é preciso se desvencilhar. Entretanto, se esta positivação da 
natureza do corpo feminino pode ser reconhecida como um esforço em direção à luta pela autonomia reprodutiva das mulheres, por outro lado, a essencialização de uma noção de natureza universal pode instaurar armadilhas sobre as quais tentamos chamar a atenção nesse artigo.

\section{REFERÊNCIAS}

BADINTER, Elisabeth. Um amor conquistado: o mito do amor materno. Rio de Janeiro: Editora Nova Fronteira, 1985.

BADINTER, Elisabeth. O conflito: a mulher e a mãe. Rio de Janeiro: Record, 2010.

BLEIER, Ruth. Science and Gender: A Critique of Biology and Its Theories on Women. New York: Pergamon Press, 1988.

BOWLBY, John. Attachment. New York: Basic Books, 1999.

CARNEIR0, Rosamaria. De perto e de longe do que seria natural, mais natural e/ou humanizado: uma etnografia de grupos de preparo para o parto. In:

FLEISCHER, Soraya; FERREIRA, Jaqueline. Etnografia em serviços de saúde. Rio de Janeiro: Garamond, 2014, p. 243-265.

FAUSTO-STERLING, Anne. Myths of Gender: biological theories about women and men. New York: Basic Books, 1992.

FILLOD, Odile. Oxytocin as Proximal Cause of 'Maternal Instinct': Weak Science, Post-Feminism, and the Hormones Mystique. In: SCHMITZ, Sigrid; HÖPPNER, Grit. Gendered Neurocultures: Feminist and Queer Perspectives on Current Brain Discourses. Viena: Zaglossus, 2014, p. 239-256.

HARAWAY, Donna. Primate Visions: Gender, Race, and Nature in the World of Modern Science. New York: Routledge, 1989.

KELLER, Evelyn Fox. The Gender/Science System: or, Is Sex to Gender as Nature Is to Science? (1987) In: BIAGIOLI, Mario. The Science Studies reader. New York: Routledge, 1999, p. 234-242.

LAQUEUR, Thomas. Inventando o sexo: corpo e gênero dos gregos a Freud. Rio de Janeiro: Relume Dumará, 2001.

MANICA, Daniela. A desnaturalização da menstruação: hormônios contraceptivos e tecnociência. Horizontes Antropológicos, ano 17, n. 35, p. 198-226, 2001. 
NUCCI, Marina. "0 sexo do cérebro": uma análise sobre gênero e ciência. In: Secretaria de Políticas para as Mulheres. (Org.). 60 Prêmio Construindo a Igualdade de Gênero - Redações, artigos científicos e projetos pedagógicos premiados. Brasília: Presidência da República, Secretaria de Políticas para as Mulheres, 2010 p. 31-56.

ODENT, Michel. A cientificação do amor. São Paulo: Terceira Margem, 2000. ODENT, Michel. O renascimento do parto. Florianópolis: Saint Germain, 2002. OUDSHOORN, Nelly. Beyond the natural body: an archeology of sex hormones. London: Routledge, 1994.

POMB0, Carolina. A mãe e o tempo: ensaio da maternidade transitória. Rio de Janeiro: 2013.

POMBO, Carolina; NUCCI, Marina. Por que somos mamíferas? [2014] Disponível em: < http://maetempo.net/2014/05/16/por-que-somos-mamiferas/>. Acesso em 22 fev 2015.

ROHDEN, Fabíola. "O homem é mesmo a sua testosterona": promoção da andropausa e representações sobre sexualidade e envelhecimento no cenário brasileiro. Horizontes Antropológicos, ano 17, n. 35, p. 162-196, 2011.

ROHDEN, Fabíola. Império dos hormônios e a construção da diferença entre os sexos. História, Ciência, Saúde - Maguinhos, v. 15, supl., p. 133-152, 2008.

ROBAYO, Margarida. Leite: Notas sobre a cruzada da amamentação. Revista Piauí, n. 98, p. 54-58, novembro, 2014

SCHIEBINGER, Londa. Skeletons in the Closet: The first illustrations of the Female Skeleton in Eighteenth-Century Anatomy. Representations, n. 14, p. 42-82, 1986.

SCHIEBINGER, Londa. Mamíferos, primatologia e sexologia. In: PORTER, Roy; TECH, Mikolas. Conhecimento sexual, ciência sexual. São Paulo: Editora Unesp, 1998, p. 219-246.

TORNQUIST, Carmen. Armadilhas da nova era: natureza e maternidade no ideário da humanização do parto. Revista Estudos Feministas, v. 10, n. 2, p. 483-492, 2002.

WIJNGAARD, Marianne. Reinventing the Sexes: the biomedical construction of femininity and masculinity. Bloomingtom Indianapolis: Indiana Univ. Press, 1997. 


\section{FONTES}

BRUM, Kalu. O olhar [s.d.]. Disponível em:

< http://vilamamifera.com/olharmamifero/o-olhar/> . Acesso em: 25 fev 2015.

BRUM, Kalu. Quando nascer rima com prazer [2014a]. Disponivel em:

$<$ http://vilamamifera.com/olharmamifero/quando-nascer-rima-com-prazer/>. Acesso em: 25 fev 2015.

BRUM, Kalu. 6 passos para ter um orgasmo no parto [2014b]. Disponivel em: $<$ http:/vilamamifera.com/olharmamifero/6-passos-para-ter-um-orgasmo-noparto/>. Acesso em: 25 fev 2015.

BRUM, Kalu. Cada bebê bem parido muda o mundo para sempre [2014c]. Disponível em: < http://vilamamifera.com/olharmamifero/cada-bebe-bemparido-muda-o-mundo-para-sempre/> . Acesso em 25 fev 2015.

BRUM, Kalu. Parir e amamentar não é pornô [2014d]. Disponível em: $<$ http://vilamamifera.com/cafemae/parir-e-amamentar-nao-e-porno/>. Acesso em 25 fev 2015.

DANELON, Fernanda. Parir e Gozar [2009]. Disponível em:

$<$ http://revistatpm.uol.com.br/revista/87/reportagens/parir-e-gozar.html >. Acesso em: 25 fev 2015.

KASIN, Valentine. Orquestra barmônica do parto por Mayra Calvette [2014].

Disponivel em: < http://maedepeso.com.br/2014/10/01/orquestra-harmonica-doparto-por-mayra-calvette-2/>. Acesso em 25 fev 2015. 